\title{
A strong-motion hot spot of the 2016 Meinong, Taiwan, earthquake $\left(M_{w}=6.4\right)$
}

\author{
Hiroo Kanamori ${ }^{1, *}$, Lingling Ye ${ }^{1}$, Bor-Shouh Huang ${ }^{2}$, Hsin-Hua Huang ${ }^{1,6}$, Shiann-Jong Lee ${ }^{2}$, Wen-Tzong \\ Liang ${ }^{2}$, Yen-Yu Lin ${ }^{1,2}$, Kuo-Fong $\mathrm{Ma}^{3}$, Yih-Min $\mathrm{Wu}^{4,5}$, and Te-Yang Yeh ${ }^{2}$ \\ ${ }^{1}$ Seismological Laboratory, California Institute of Technology, Pasadena, California, USA \\ ${ }^{2}$ Institute of Earth Sciences, Academia Sinica, Taipei City, Taiwan \\ ${ }^{3}$ Department of Earth Sciences, National Central University, Taoyuan City, Taiwan \\ ${ }^{4}$ Department of Geosciences, National Taiwan University, Taipei City, Taiwan \\ ${ }^{5}$ National Center for Research on Earthquake Engineering, National Applied Research Laboratories, Taipei City, Taiwan \\ ${ }^{6}$ Department of Geology and Geophysics, University of Utah, Salt Lake City, UT, USA
}

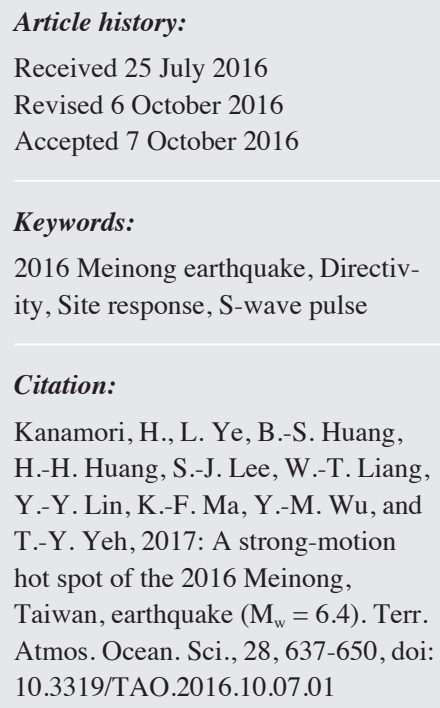

Citation:

Kanamori, H., L. Ye, B.-S. Huang, H.-H. Huang, S.-J. Lee, W.-T. Liang, Y.-Y. Lin, K.-F. Ma, Y.-M. Wu, and T.-Y. Yeh, 2017: A strong-motion hot spot of the 2016 Meinong, Taiwan, earthquake $\left(\mathrm{M}_{\mathrm{w}}=6.4\right)$. Terr. Atmos. Ocean. Sci., 28, 637-650, doi: 10.3319/TAO.2016.10.07.01

\begin{abstract}
Despite a moderate magnitude, $\mathrm{M}_{\mathrm{w}}=6.4$, the 5 February 2016 Meinong, Taiwan, earthquake caused significant damage in Tainan City and the surrounding areas. Several seismograms display an impulsive S-wave velocity pulse with an amplitude of about $1 \mathrm{~m} \mathrm{~s}^{-1}$, which is similar to large $\mathrm{S}$-wave pulses recorded for the past several larger damaging earthquakes, such as the 1995 Kobe, Japan, earthquake $\left(M_{w}=6.9\right)$ and the 1994 Northridge, California, earthquake $\left(\mathrm{M}_{\mathrm{w}}=6.7\right)$. The observed PGV in the Tainan area is about 10 times larger than the median PGV of $\mathrm{M}_{\mathrm{w}}=6.4$ crustal earthquakes in Taiwan. We investigate the cause of the localized strong ground motions. The peak-to-peak ground-motion displacement at the basin sites near Tainan is about 35 times larger than that at mountain site with a similar epicentral distance. At some frequency bands $(0.9-1.1 \mathrm{~Hz})$, the amplitude ratio is as large as 200 . Using the focal mechanism of this earthquake, typical "soft" and "hard" crustal structures, and directivity inferred from the observed waveforms and the slip distribution, we show that the combined effect yields an amplitude ratio of 17 to 34 . The larger amplitude ratios at higher frequency bands can be probably due to the effects of complex 3-D basin structures. The result indicates that even from a moderate event, if these effects simultaneously work together toward amplifying ground motions, the extremely large ground motions as observed in Tainan can occur. Such occurrences should be taken into consideration in hazard mitigation measures in the place with frequent moderate earthquakes.
\end{abstract}

\section{INTRODUCTION}

The 5 February 2016 Meinong earthquake (U.S. Geological Survey hypocenter parameters: 19:57:27 UTC, $\mathrm{M}_{\mathrm{w}}$ $=6.4,22.94^{\circ} \mathrm{N}, 120.60^{\circ} \mathrm{E}, 23.0 \mathrm{~km}$ ) which occurred near the City of Tainan, Taiwan, caused severe damage with 117 fatalities and collapse of tall buildings despite its moderate magnitude (Fig. 1a). It is the most damaging earthquake in Taiwan since the $1999 \mathrm{M}_{\mathrm{w}}=7.6 \mathrm{Chi}-\mathrm{Chi}$ earthquake. The peak local intensity reported by the Central Weather Bureau (CWB) of Taiwan was 7, the highest on the Taiwan intensity scale with PGA $>400 \mathrm{~cm} \mathrm{~s}^{-2}$. A concise summary of the tectonic framework of this earthquake is given by Huang et

\footnotetext{
* Corresponding author

E-mail:hiroo@gps.caltech.edu
}

al. (2016).

Immediately after the occurrence of the event, the waveforms of local ground motions recorded with the Taiwan Early Warning System Palert (Wu et al. 2013) were released. The Palert records used in this study are available to the public (Wu et al. 2016) and can be downloaded from the cloud disk at the National Taiwan University (https:// www.space.ntu.edu.tw/navigate/s/5CDFA7C2CFD7487FB 84E2CE3F7376C33QQY). To our surprise, the record from the station W21B, about $27 \mathrm{~km} \mathrm{WNW} \mathrm{[} \phi$ (azimuth $\left.)=299^{\circ}\right]$ from the epicenter, displayed an impulsive velocity pulse with an amplitude of about $1 \mathrm{~m} \mathrm{~s}^{-1}$ (Fig. 1b). As shown in Fig. 2, the W21B velocity pulse is comparable to the velocity pulses recorded for several damaging earthquakes in the 


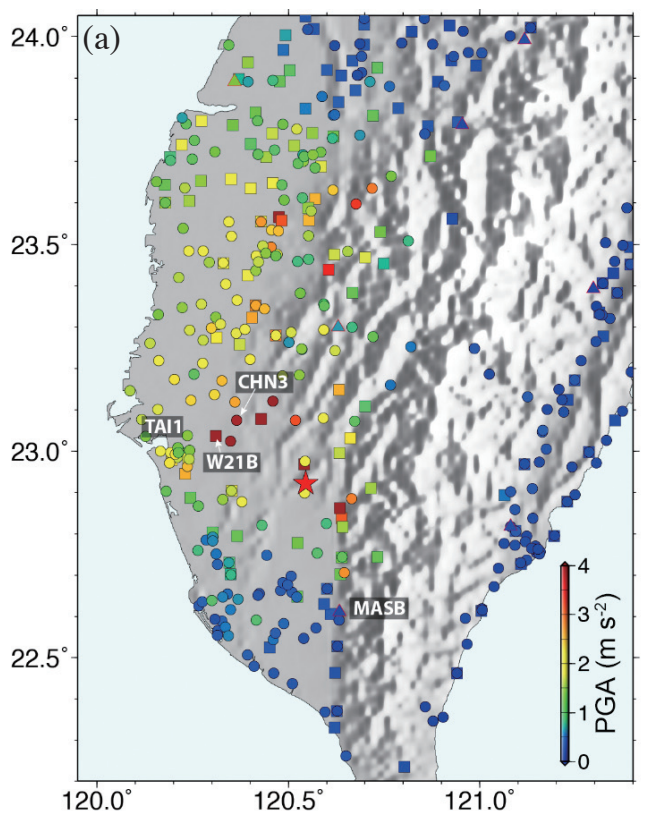

(b) W21B, E-W
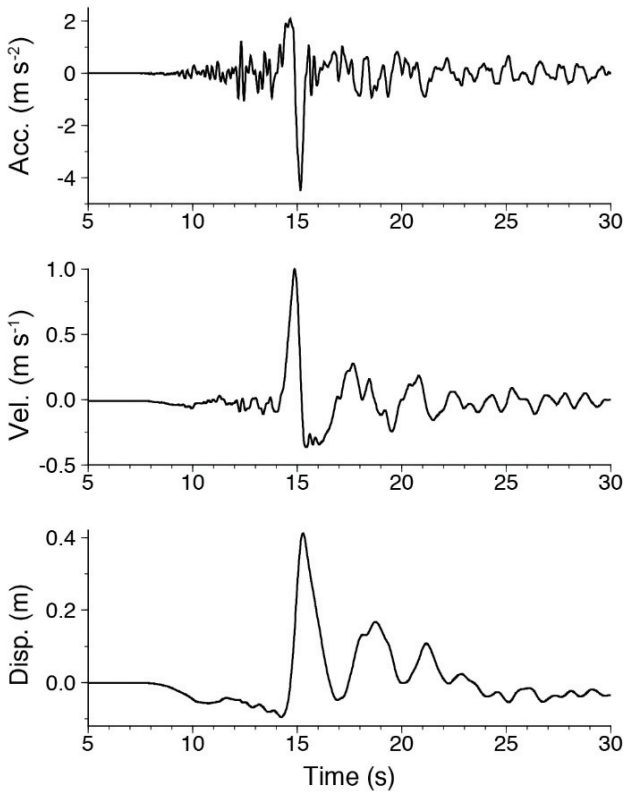

Fig. 1. (a) PGA distribution of the 2016 Meinong earthquake (circles: CWB stations; squares: Palert stations; triangles: BATS stations). The epicenter is indicated by a star, and the 4 stations discussed are indicated by their station names. (b) The EW component ground-motion acceleration, velocity and displacement recorded at a Palert station W21B. The ground-motion waveforms recorded at station MASB are shown in Figs. 5, 11, and 13.

\section{Ground-Motion Velocity from Large Earthquakes}

Modified from Hall et al. (1995)
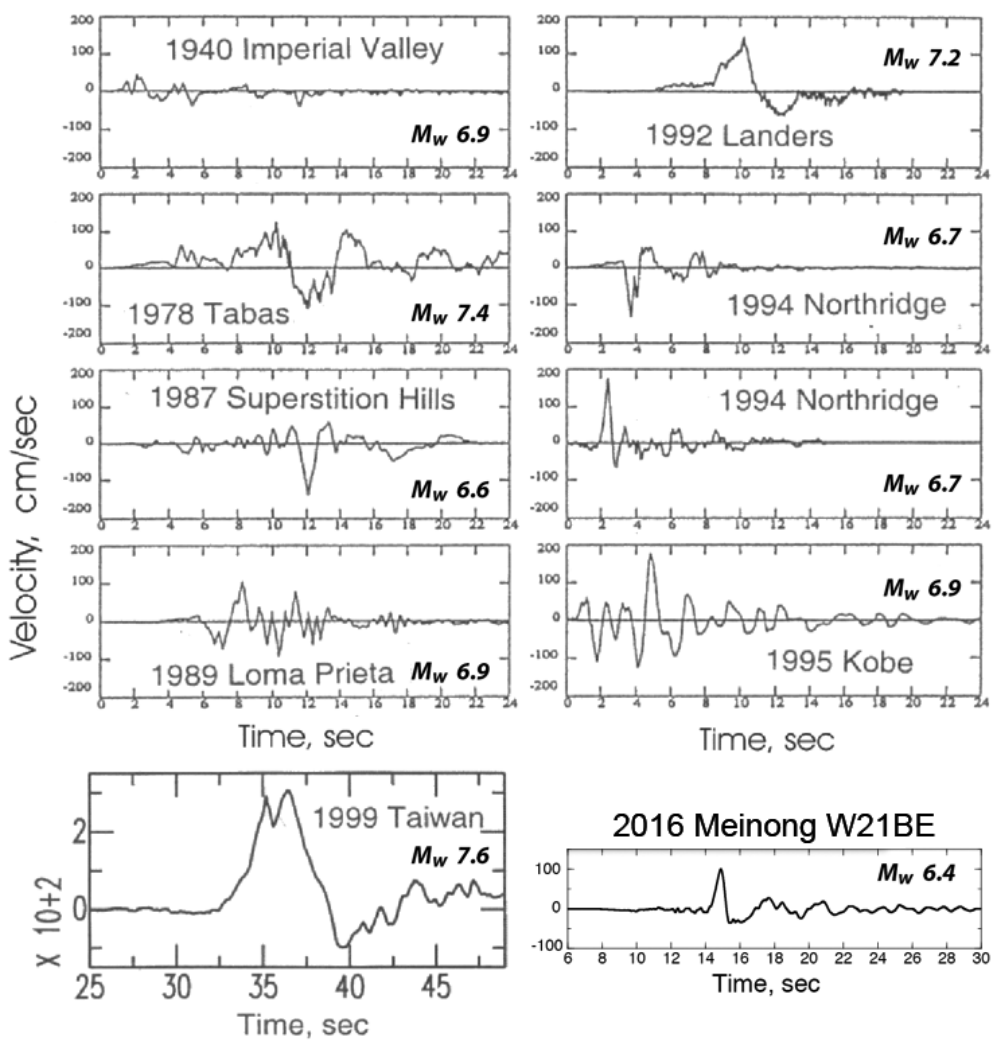

Time, sec

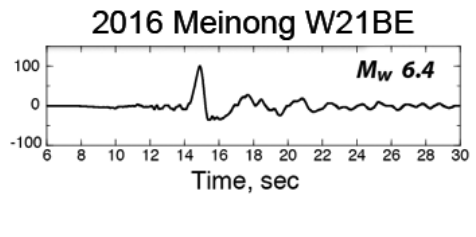

Fig. 2. Ground-motion velocity recorded at W21B (EW component) for the 2016 Meinong earthquake compared with the S-wave pulses of damaging large earthquakes in the past (modified from Hall et al. 1995). Note the similarity of the waveforms between the 1994 Northridge earthquake and the 2016 Meinong earthquake. 
past, especially the one recorded at the Olive View Hospital during the 1994 Northridge, California, earthquake. Hall et al. (1995) and Heaton et al. (1995) emphasized the engineering implications of these large velocity pulses especially for the safety of tall buildings. As will be shown later, the records at a few other stations, like TAI1 (CHY078) and CHN3 (CHY089) (locations are shown in Fig. 1a) near W21B display equally impulsive large velocity pulses. Also shown in Fig. 1 is the location of station MASB which will be used as a reference bedrock site. We will compare the ground motions at soft basin sites to those at this bedrock station.

This study is motivated by these unusual observations, and discusses the hazard implications of ground motions from moderate earthquakes in urban environments.

\section{OVERALL SOURCE CHARACTERISTICS OF THE 2016 MEINONG EARTHQUAKE}

Although our main objective is to understand the cause of the unusually strong ground motions, rather than to perform detailed analyses of the rupture mechanism of this particular earthquake, we first investigate the overall source characteristics of this earthquake over a broad frequency band. A good source model is a prerequisite for understanding the excitation of seismic waves which ultimately determines the nature of ground motions.

\subsection{W Phase Inversion}

Since the crustal structure of Taiwan is complex, varying rapidly from thick basin structures on the west coast to bed-rock sites in the central mountains, propagation of short period waves is complex. To avoid the complex propagation effects, we first study long-period $\mathrm{W}$ phases recorded with the Taiwan BATS network (IESAS 1996; http://bats.earth. sinica.edu.tw) and determine the long-period characteristics up to a period of $150 \mathrm{~s}$. The method is described in Kanamori and Rivera (2008), but for applications to moderate regional events, we use a structure shown in Table 1, and a higher frequency band $0.0067 \mathrm{~Hz}(150 \mathrm{~s})$ to $0.02 \mathrm{~Hz}(50 \mathrm{~s})$ than the standard frequency band $[0.001 \mathrm{~Hz}(1000 \mathrm{~s})$ to $0.005 \mathrm{~Hz}$ (200 s)]. Figure 3 shows the result. The best double-couple solution is given by strike/dip/rake $(\mathrm{s} / \mathrm{d} / \mathrm{r})=295^{\circ} / 30^{\circ} / 37^{\circ}$ and $172^{\circ} / 73^{\circ} / 115^{\circ}$ and is similar to those obtained by various investigators using different methods, different data sets, and different frequency bands [e.g., Huang et al. (2016), Lee et al. (2016), also http://tesis.earth.sinica.edu.tw/showDetail. php?date $=\% 272016-02-06 \% 27 \&$ time $=\% 2703: 57: 27 \% 27]$.

Thus, despite the extreme lateral heterogeneity of the structure, the geometry of the source appears to be well constrained at long period. The nearest stations MASB to the south is shown in Fig. 1a, $\Delta$ (distance) $=34 \mathrm{~km}, \phi$ (azimuth) $=165^{\circ}$.

\subsection{Teleseismic Body-Wave Inversion}

We next investigate teleseismic $\mathrm{P}$ and $\mathrm{SH}$ waves over a period range from 2 - 30 s. Figure 4 summarizes the result of teleseismic body-wave inversion. The method used is similar to that described in Hartzell and Heaton (1983), and the code used is based on the one archived at http://wwweic.eri.u-tokyo.ac.jp/ETAL/KIKUCHI but with extensive modifications and additions made at the University of California, Santa Cruz, described in Ye et al. (2016).

The crustal structure used for inversion is shown in Table 2. We used the mechanism $\mathrm{s} / \mathrm{d} / \mathrm{r}=281^{\circ} / 24^{\circ} / 23.8^{\circ}$ given by the initial solution of the Global Centroid Moment Tensor (GCMT) Project, and the rupture speed used for inversion shown in Fig. 4 is $3 \mathrm{~km} \mathrm{~s}^{-1}$. We obtain a seismic moment of $\mathrm{M}_{0}=5.05 \times 10^{18} \mathrm{Nm}\left(\mathrm{M}_{\mathrm{w}}=6.4\right)$. Figure 4a shows the moment-rate function viewed from large distance normal to the fault plane. This should be regarded as an "average" moment rate function. As will be shown later, the momentrate function viewed from different azimuths varies depending on directivity. Although the total duration of the source is about $17 \mathrm{~s}$, the main pulse is only about $5 \mathrm{~s}$ long. The red curve on Fig. $4 \mathrm{~b}$ shows the moment-rate spectrum at frequencies higher than $0.05 \mathrm{~Hz}$ estimated from the observed displacement records. The dashed curve in Fig. $4 \mathrm{~b}$ is the reference omega-squared moment-rate spectrum computed with a stress parameter of $3 \mathrm{MPa}$ (see Ye et al. 2016). We compute the radiated energy $E_{R}$ from the observed spectrum (red curve) as $E_{R}=2.81 \times 10^{14} \mathrm{~J}$ with a scaled energy $E_{R} /$ $\mathrm{M}_{0}=5.56 \times 10^{-5}$. Figure $4 \mathrm{c}$ shows the $\mathrm{P}$ and $\mathrm{SH}$ radiation patterns. Figure $4 \mathrm{~d}$ shows the slip distribution on the fault dipping $24^{\circ}$ to the north. The NS trending steep nodal plane could be used as the fault plane but the north dipping plane can explain the directivity better. From the waveform inversion alone, we cannot determine which of the 2 nodal panes is the fault plane. The analyses by Huang et al. (2016) and Lee et al. (2016) suggest that the static horizontal displacement field appears to favor the north-dipping nodal plane as the fault plane. The rake angle and the slip function are shown on each $4 \times 4 \mathrm{~km}^{2}$ subfault. Note that the local slip function is very short, $0.5-1 \mathrm{~s}$, on most subfaults. This slip distribution is in general similar to that obtained by Lee et al. (2016) in which local and global seismic data and geodetic

Table 1. Crustal structure used for $\mathrm{W}$ phase inversion. $\mathrm{H}$ : thickness; $\alpha$ : P-wave speed; $\beta$ : $\mathrm{S}$ wave speed; $\rho$ : density. Crust is underlain by a PREM-like mantle structure.

\begin{tabular}{cccc}
\hline $\mathbf{H}(\mathbf{k m})$ & $\boldsymbol{\alpha}\left(\mathbf{k m ~ s}^{-\mathbf{1}}\right)$ & $\boldsymbol{\beta}\left(\mathbf{k m ~ s}^{-1}\right)$ & $\boldsymbol{\rho}\left(\mathbf{g ~ c m}^{-3}\right)$ \\
\hline 18 & 6.0 & 3.5 & 2.6 \\
15 & 6.7 & 3.8 & 3.38 \\
7 & 7.7 & 4.3 & 3.38 \\
\hline
\end{tabular}



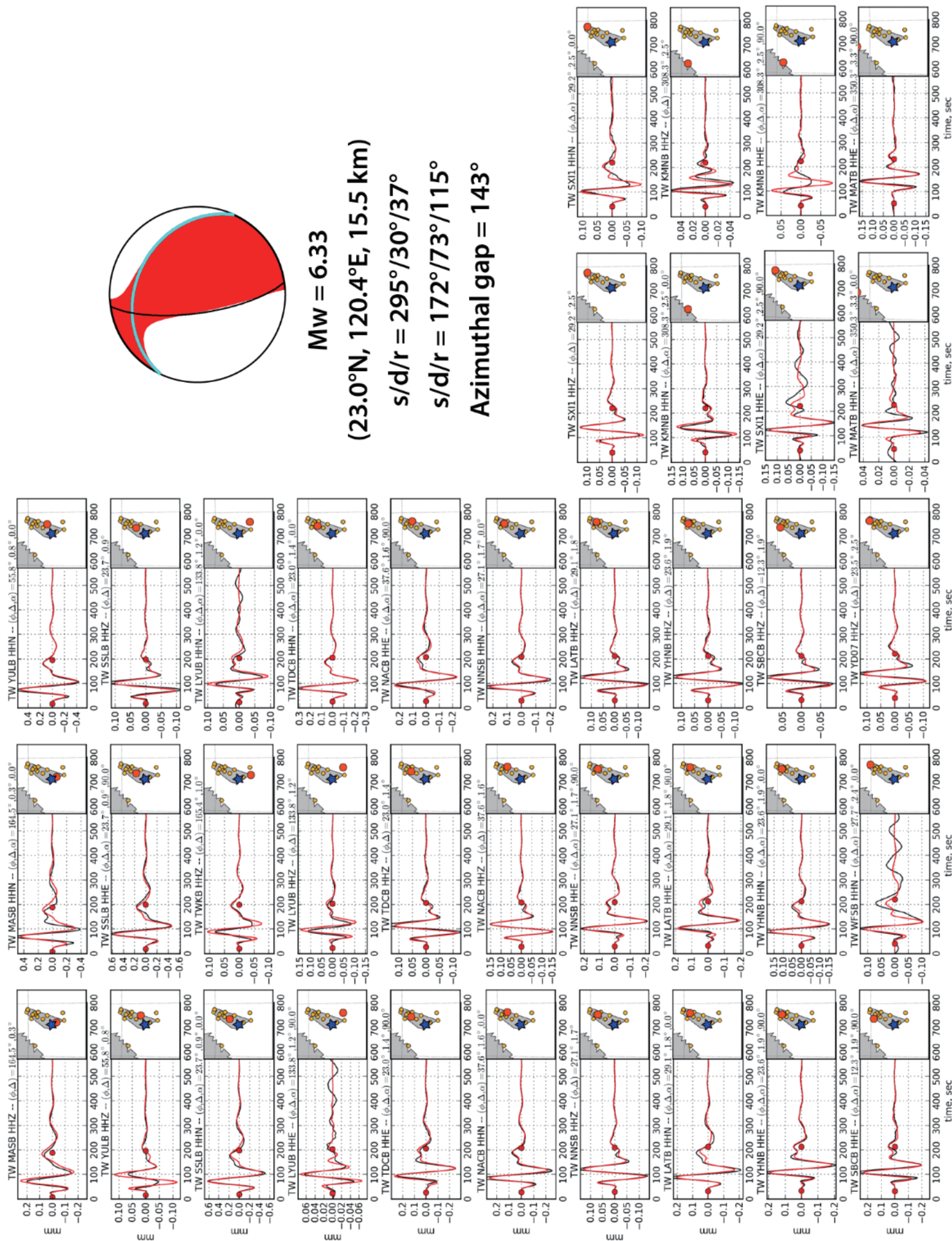

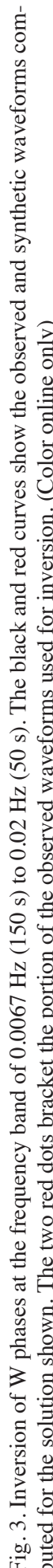



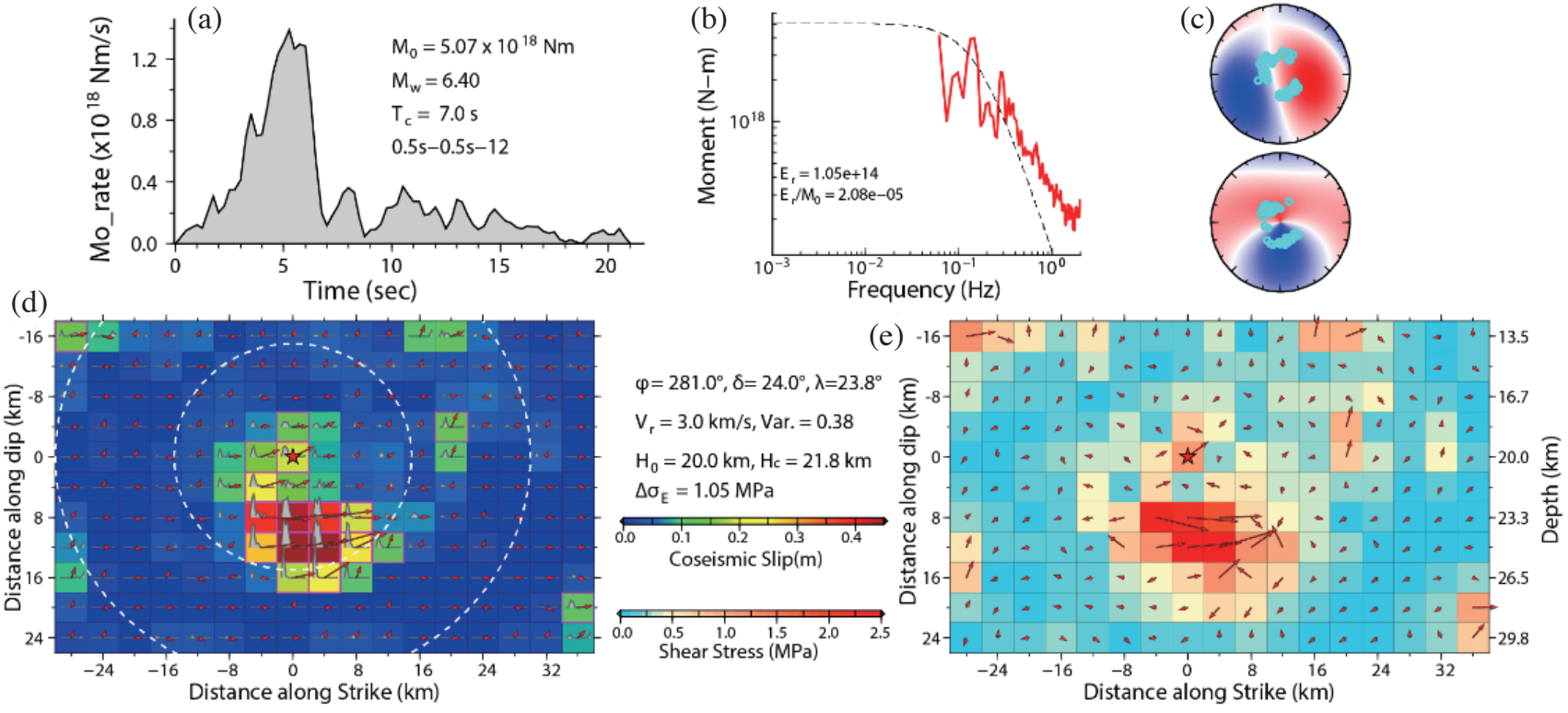

(f)
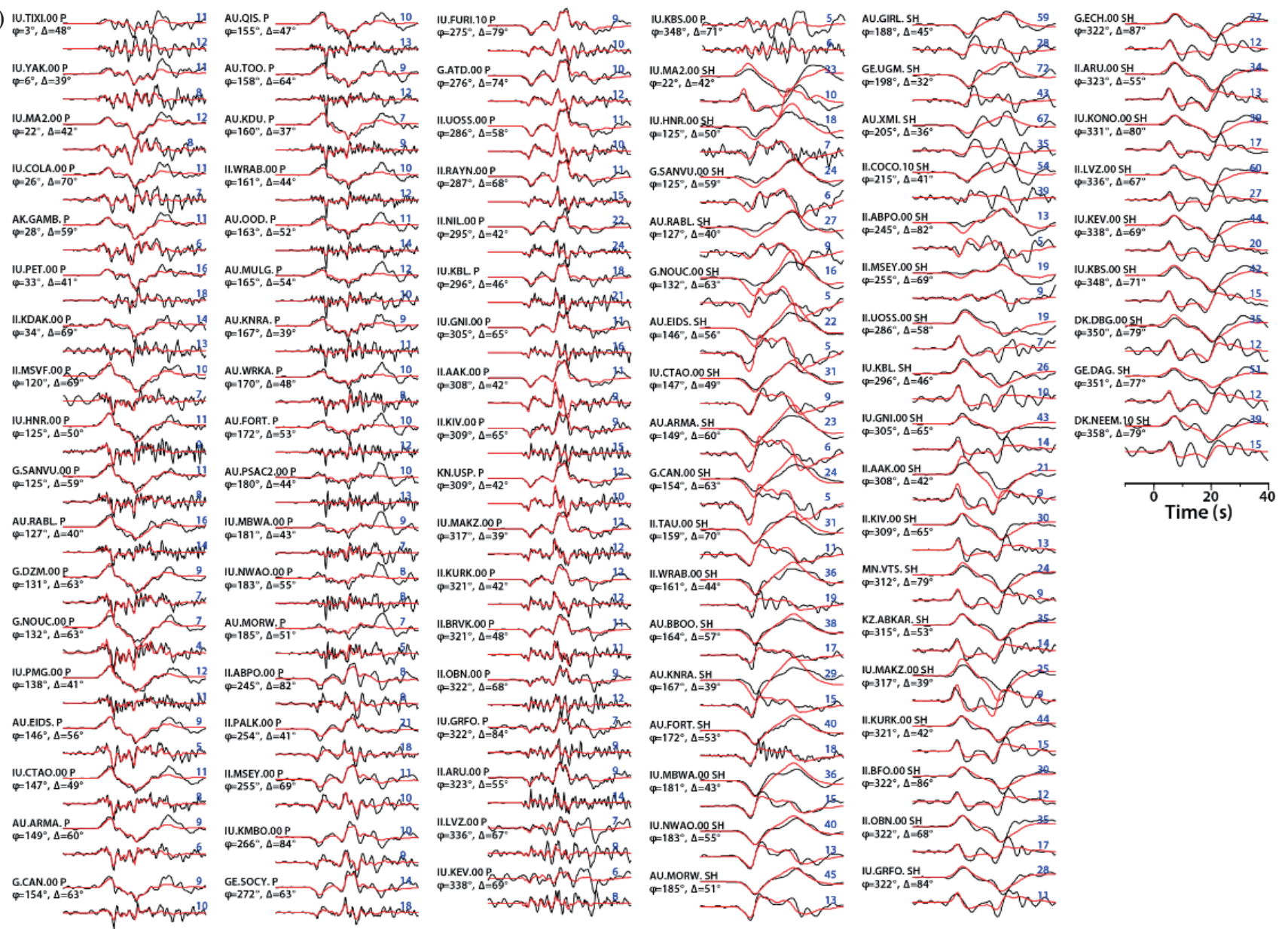

Fig. 4. Inversion of teleseismic body waves. (a) Moment-rate function and (b) moment-rate spectrum. (c) P and SH radiation patterns with the stations used for inversion. The mechanism is given by (slip/dip/rake $=281^{\circ} / 24^{\circ} / 24^{\circ}$ ), (d) Slip distribution, (e) distribution of stress drop, and (f) observed (black) and computed (red) teleseismic P and SH displacement and velocity waveforms. For each station, the first row shows the displacement and the second row shows the velocity. A rupture speed of $3 \mathrm{~km} \mathrm{~s}^{-1}$ is assumed. 
Table 2. Crustal structure used for teleseismic inversion.

\begin{tabular}{cccc}
\hline $\mathbf{H}(\mathbf{k m})$ & $\boldsymbol{\alpha}\left(\mathbf{k m ~ s}^{-1}\right)$ & $\boldsymbol{\beta}\left(\mathbf{k m ~ s}^{-1}\right)$ & $\boldsymbol{\rho}\left(\mathbf{g ~ c m}^{-3}\right)$ \\
\hline 0.7 & 2.5 & 1.2 & 2.1 \\
14.3 & 6.0 & 3.5 & 2.7 \\
9.0 & 6.6 & 3.7 & 2.9 \\
11.0 & 7.2 & 4.0 & 3.05 \\
half space & 7.8 & 4.4 & 3.5 \\
\hline
\end{tabular}

data were jointly used. Figure $4 \mathrm{e}$ shows the distribution of stress drop with the average of about $1 \mathrm{MPa}$, but the absolute value depends on the assumed rupture speed. If we use a rupture speed of 2.5 and $3.5 \mathrm{~km} \mathrm{~s}^{-1}$, the stress drop is 1.7 and $0.6 \mathrm{MPa}$, respectively. Figure $4 \mathrm{f}$ compares the observed and synthetic teleseismic P and SH waveforms showing overall good agreement. Although teleseismic data do not have enough resolution to determine the detailed slip distribution for a small to moderate event like this, the recent high-quality broadband waveforms at many stations as shown in Fig. $4 \mathrm{f}$ contain important information of the event. We include these waveforms here because they are often useful for checking some details of the source characteristics.

\section{INTERPRETATION OF LARGE GROUND MOTIONS}

To interpret the details of ground motions, ideally we should invert all the regional and teleseismic data together using a detailed three-dimensional (3-D) structure in Taiwan. Although extensive studies have been made in Taiwan to determine 3-D crustal structures, given the extreme lateral variations of the site response near the epicentral area and the relatively short period waves involved, a complete 3-D inversion study is not practical. Here, we take a simpler approach by examining each important ground-motion record after having determined the overall gross source characteristics as shown in Figs. 3 and 4. Our objective is to understand why such localized strong ground motions were produced by this earthquake, rather than to explain every detail of the observed records. Since the events in the future are unlikely to occur in exactly the same way as the events in the past, we believe that a good understanding of the special circumstance which caused the observed strong-motion hot spot is critically important for implementing comprehensive hazard mitigation measures in the future.

\subsection{Comparison of the Records at Stations W21B and MASB}

To investigate approximate spatial variability of ground motions, first we compare the ground motions at W21B and
MASB (Fig. 5). These stations are among the closest stations with very different ground-motion periods and amplitudes. As shown in Fig. 5, the pulse width is $2.7 \mathrm{~s}$ at W21B while it is $5.5 \mathrm{~s}$ at MASB. The peak-to-peak amplitude at W21B (EW component) is approximately 35 times larger than that at MASB (EW component). The azimuthal amplitude variation of this magnitude has been seldom observed. The factor of 35 is the amplitude ratio of the whole trace. If we compare the amplitude ratio at different frequency bands, the amplification factors are $35,160,120,140$, and 210 for the frequency bands $0.1-0.3,0.3-0.5,0.5-0.7,0.7-0.9$, and $0.9-1.1 \mathrm{~Hz}$, respectively (Fig. 6). The observed large displacement amplitude ratios are also reflected in PGA (ratio $=\left[450 \mathrm{~cm} \mathrm{~s}^{-2}(\right.$ W21B_E $\left.)\right] /\left[10.9 \mathrm{~cm} \mathrm{~s}^{-2}\right.$ (MASB_E) $\left.]=41\right)$, PGV(ratio $=\left[100 \mathrm{~cm} \mathrm{~s}^{-1}\right.$ (W21B_E) $] /\left[0.9 \mathrm{~cm} \mathrm{~s}^{-1}\right.$ (MASB_E) $]$ $=111$ ), and in the spectral acceleration and spectral velocity as shown in Fig. 7; the ratio of spectral amplitude at the period of 1 to $2 \mathrm{~s}$ is (W21B_E)/(MASB_E) $=150$ to 160 .

Note that these ratios are the amplitude ratios of $\mathrm{W} 21 \mathrm{~B}$ to MASB, and not the amplification factor at W21B. According to Liu and Tsai (2005), the median values of PGA and PGV of $\mathrm{M}_{\mathrm{w}}=6.4$ crustal earthquakes in Taiwan are approximately 100, and $9 \mathrm{~cm} \mathrm{~s}^{-1}$, respectively (Figs. 3 and 4 of Liu and Tsai 2005). Thus, these observations mean that PGA and PGV at W21B are, respectively, about 4.5 and 10 times larger than the median value for Taiwan crustal earthquakes.

\subsection{Factors that Control the Ground-Motion Amplitude}

We now examine why the amplitude is so different between W21A and MASB by considering three factors: (1) geometrical effect of the radiation pattern; (2) site and propagation effect; and (3) directivity.

\subsubsection{Crustal Structure}

To make these comparisons, we need to know the crustal structures for this area. Since we do not have a specific model for this area, we characterize the structures by a "hard" and "soft" model shown in Table 3 and Fig. 8. Several crustal models have been presented for Taiwan (e.g., Hwang et al. 2003; Lin et al. 2009; Wu and Huang 2013; Huang et al. 2013, 2014; Kuo et al. 2015). To represent the soft basin structure for the station W21B, we refer to the $\mathrm{S}$ wave structure in the shallow crust shown in Lin et al. (2009) for a profile near Jiali (Lat. $23.17^{\circ} \mathrm{N}$, Long. $120.17^{\circ} \mathrm{E}$ ). We construct a structure for a "soft" path by combining the shallow structure given by Lin et al. (2009) with a structure for a deeper crust taken from Huang et al. (2014). For the "hard" path, we simply remove the top 5 soft layers (layer 4 and layer 5 are identical) from the structure for the "soft" path. The structures shown in Table 3 and Fig. 8 are constructed this way. We do not attempt to model the exact propagation effect, and our objective is to 

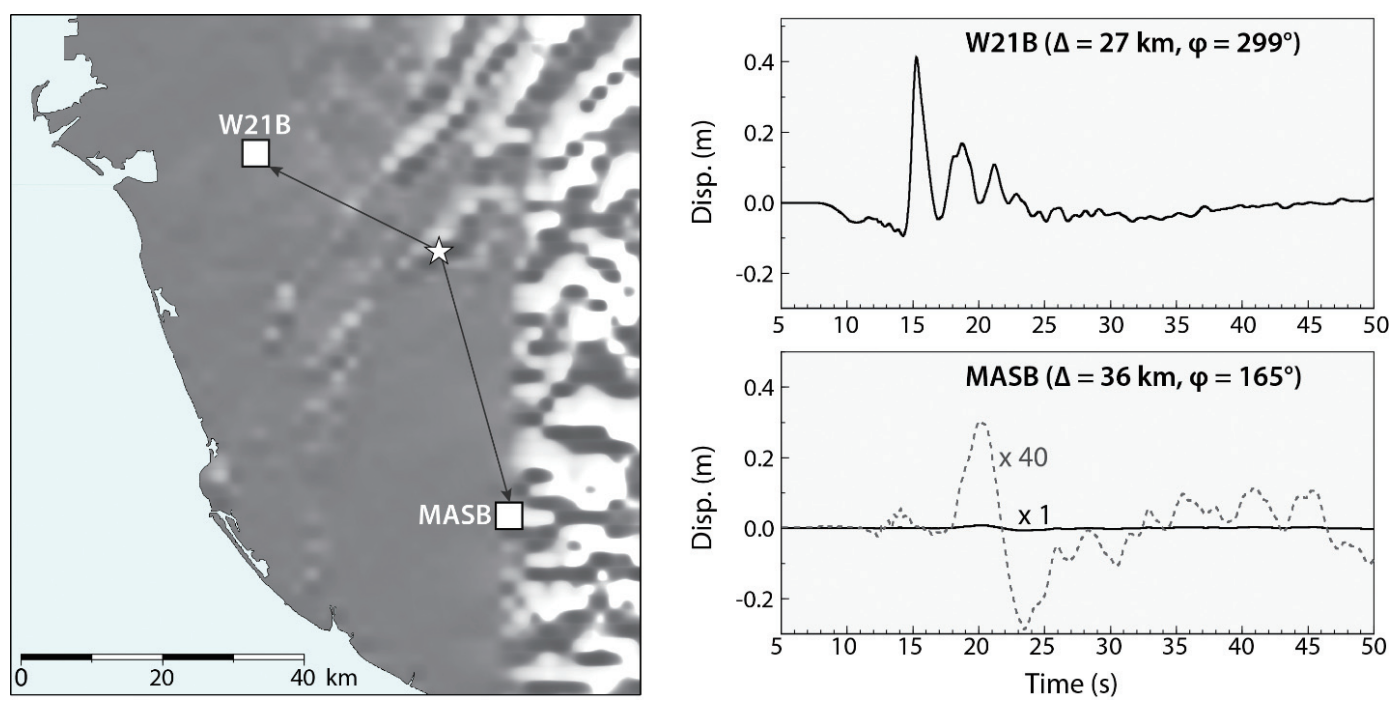

Fig. 5. Comparison of the EW component displacement waveforms at the stations W21B and MASB. On the plot for MASB, the black curve (marked as $\times 1$ ) is the plot with the same amplitude scale as that for W21B, and the gray curve $(\times 40)$ shows the displacement multiplied by 40 , indicating that the trace amplitude at W21B is about 35 times larger than that at MASB. (Color online only)
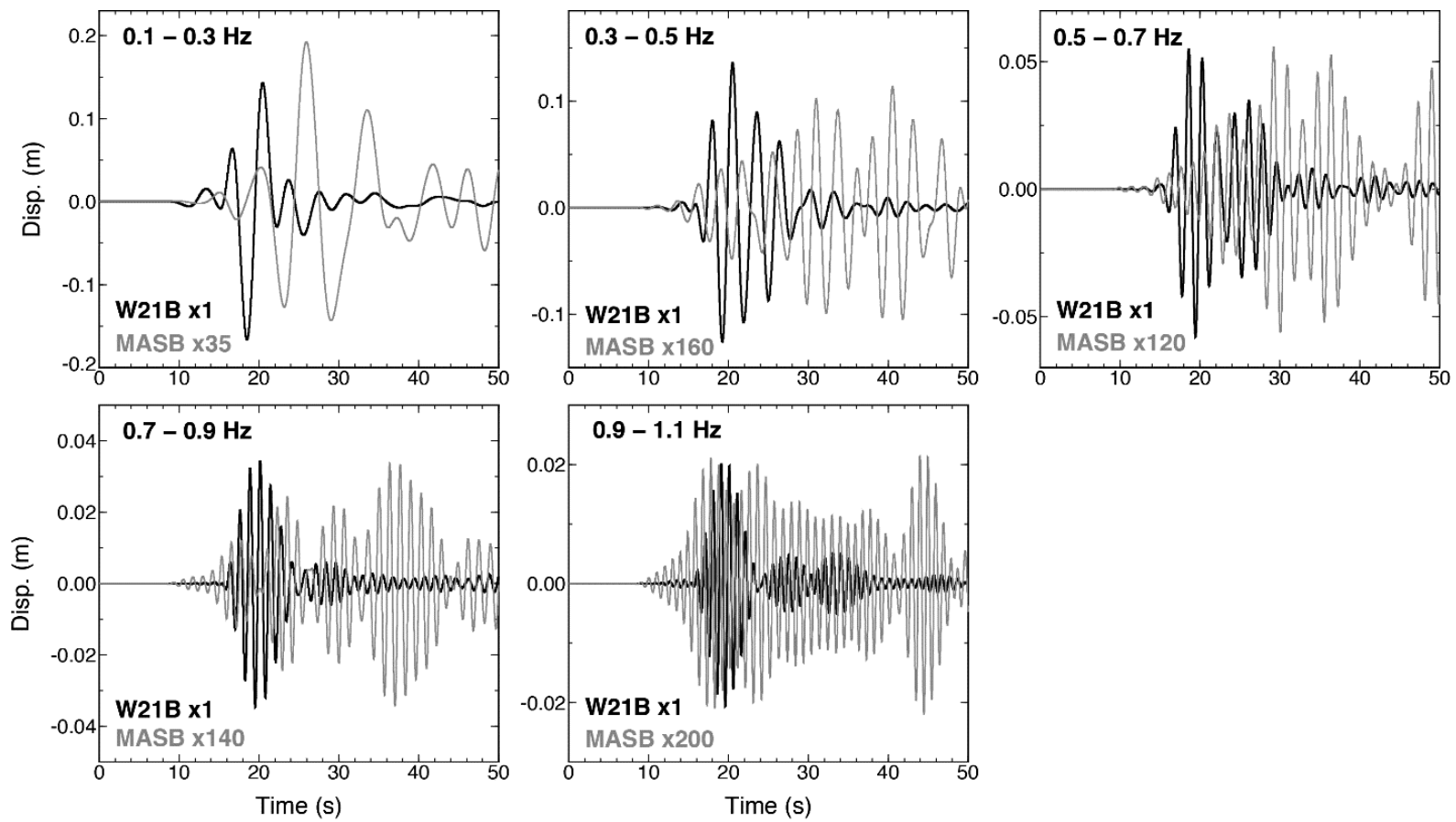

Fig. 6. Comparison of the amplitude at W21B (black) and at MASB (gray) at 5 frequency bands. For each frequency band the records are Butterworth band-pass filtered. For comparison, the MASB record is multiplied by a factor given at the lower left of each figure. Note that at the frequency band $0.3-0.5 \mathrm{~Hz}(2-3.3 \mathrm{~s})$; the amplitude ratio is about 160 . 

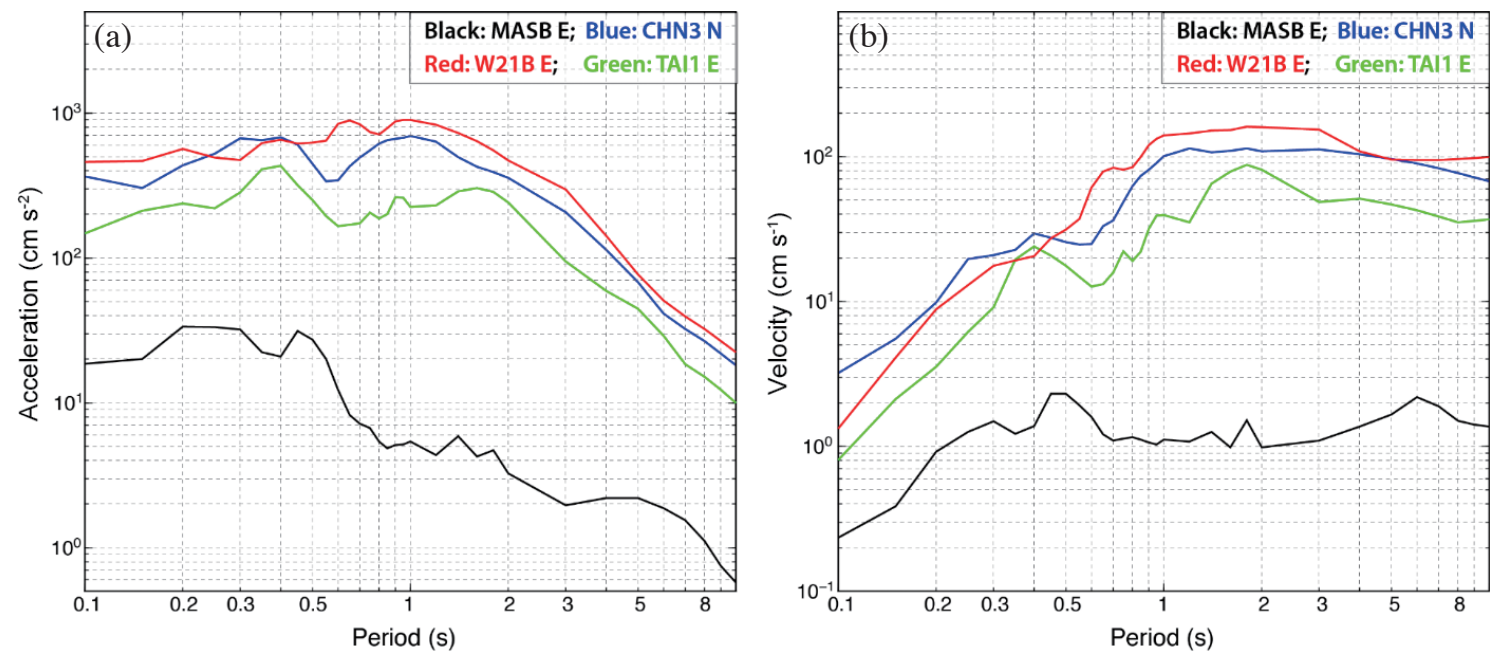

Fig. 7. Spectral acceleration (a) and spectral velocity (b) computed for the records at MASB (EW component), W21B (EW component), CHN3 (NS component), and TAI1 (EW component). Damping is 5\%. (Color online only)

Table 3. Crustal structure used for modeling local wave-field. The structure shown is for the "soft" structure model, and the "hard" structure model is constructed by removing the top 5 layers.

\begin{tabular}{ccccccc}
\hline Layer & $\mathbf{H}(\mathbf{k m})$ & $\boldsymbol{\alpha}\left(\mathbf{k m ~ s}^{-1}\right)$ & $\boldsymbol{\beta}\left(\mathbf{k m ~ s}^{-1}\right)$ & $\boldsymbol{\rho}\left(\mathbf{g ~ c m}^{-3}\right)$ & $\mathbf{Q}_{\alpha}$ & $\mathbf{Q}_{\beta}$ \\
\hline 1 & 0.5 & 1.5 & 0.58 & 2.0 & 40 & 20 \\
2 & 0.5 & 2.5 & 1.0 & 2.2 & 120 & 60 \\
3 & 0.5 & 2.8 & 1.2 & 2.2 & 600 & 300 \\
4 & 0.5 & 4.2 & 1.7 & 2.2 & 600 & 300 \\
5 & 0.5 & 4.2 & 1.7 & 2.2 & 600 & 300 \\
6 & 2.0 & 4.44 & 2.556 & 2.4 & 600 & 300 \\
7 & 5.0 & 5.25 & 3.035 & 2.6 & 600 & 300 \\
8 & 4.0 & 6.05 & 3.457 & 2.6 & 600 & 300 \\
9 & 4.0 & 6.36 & 3.655 & 2.7 & 600 & 300 \\
10 & 8.0 & 6.66 & 3.85 & 2.7 & 600 & 300 \\
11 & 5.0 & 7.14 & 4.103 & 2.7 & 600 & 300 \\
12 & 5.0 & 7.43 & 4.27 & 2.8 & 600 & 300 \\
13 & 15.0 & 7.71 & 4.406 & 2.8 & 600 & 300 \\
14 & 20.0 & 7.96 & 4.628 & 3.0 & 600 & 300 \\
15 & 20.0 & 8.1 & 4.629 & 3.1 & 600 & 300 \\
16 & 4.0 & 8.23 & 4.73 & 3.3 & 600 & 300 \\
\hline
\end{tabular}

assess the effect of typical crustal structures on propagation of the waves along the strikingly different structures.

\subsubsection{Radiation Pattern Effect}

The effect of the radiation pattern on the amplitude can be determined by comparing the amplitude of synthetic seismograms computed for the stations W21B and MASB using the same structure "hard" and "soft" structures. As shown in Fig. 9, the amplitude ratio W21B/MASB is about

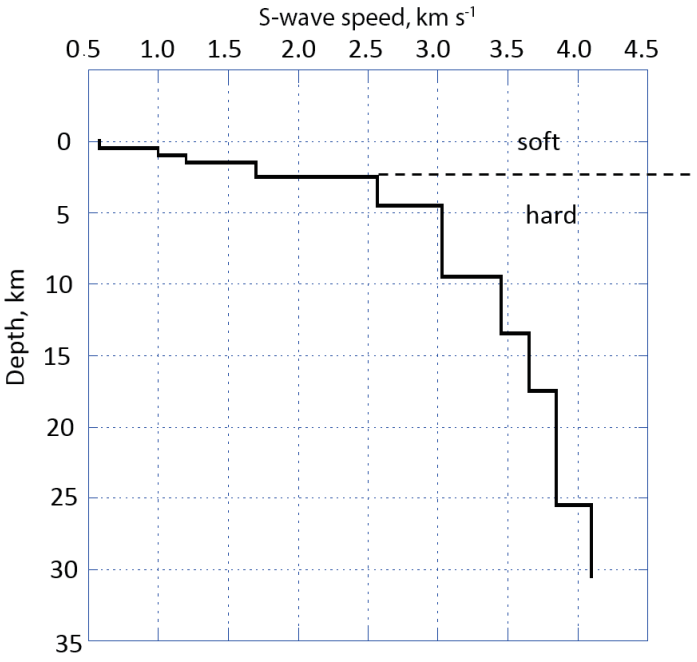

Fig. 8. S-wave vertical profile used for the "soft" structure model. The "hard" structure model is obtained by removing the top 5 layers above the depth indicated by a dashed line. (Color online only)

3 to 4 either for hard or soft structure. This ratio is for the peak-to-peak trace amplitude of the impulsive $\mathrm{S}$-wave pulse and just an approximate value.

\subsubsection{Site Effect}

Here the site effect is not the strict site response used in engineering practice; it is the amplitude ratio of the synthetics computed for a 1-D "soft" and "hard" structure shown in Fig. 8. We do not include 3-D site response effects here. 

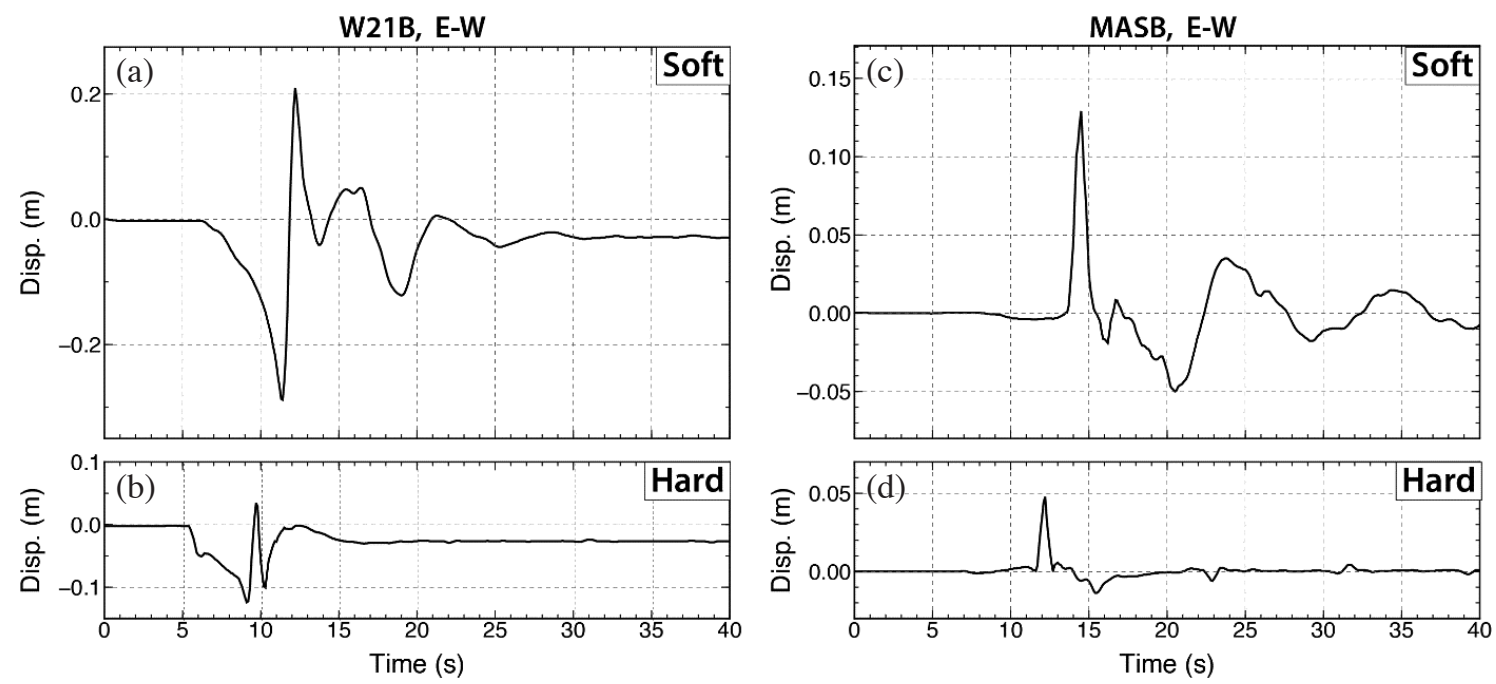

Fig. 9. Synthetic displacement waveforms computed for the stations W21B and MASB using the "soft" and "hard" structure models.

From Fig. 9, the peak-to-peak amplitude ratio of "soft" to "hard" case is about 5 for W21B and 3.5 for MASB.

For comparison, Fig. 10 shows the crustal response functions [the ratio of (amplitude at the surface)/(amplitude of incoming plane wave at the base)] (Haskell 1962) for a vertically incident SH wave for the "soft" and "hard" crust. The ratio of the response function is on the average consistent with the ratio of the trace amplitude shown in Fig. 9.

\subsubsection{Directivity}

The difference of the pulse width observed at W21B $(2.7 \mathrm{~s})$ and MASB $(5.5 \mathrm{~s})$ clearly suggests significant directivity toward W21B (azimuth $299^{\circ}$ ) (i.e., toward north-west and down-dip). The pulse width ratio of 2 suggests that the amplitude ratio due to directivity is $1 / 2$. The slip inversion of teleseismic data shown in Fig. 4 does not have sufficient resolution to accurately determine the rupture directivity. However, as shown in Figs. 4 and 11, even with the limited resolution, the rupture appears to have propagated mainly to the north from the hypocenter with a slight westward component. Since the slip near the hypocenter is small, the main pulse must be produced by a large slip patch about $10 \mathrm{~km}$ to the north of the hypocenter. Figure 11 shows the moment rate functions as viewed from various azimuths. The moment-rate function viewed from the station W21B (red) is significantly shorter than that from the station MASB (blue), which is qualitatively consistent with the observation shown in Figs. 5 and 11. However, a counter-clockwise rotation of the slip pattern by $30^{\circ}$ would make the agreement with the observation even better. Given the limited resolution of the teleseismic inversion, we consider the slip pattern is satisfactorily supportive of the observed directivity effect of about 2. For comparison, the waveforms at W21B and MASB are shown on the left side of the figure. The slip model derived from a data set including local seismic data by Lee et al. (2016) suggests stronger westward directivity.

\subsubsection{Expected Amplitude Variation}

If we combine the effects of the three factors, we get a range of amplification factor of 17 to 34 [radiation pattern (2.4 to 3.4$) \times$ path-site effect (3.5 to 5 ) $\times$ directivity (2)], which is comparable to the observed ratio 35 . However, as shown by Fig. 6, even larger ratios at high frequency bands suggest another factor caused by the 3-D basin structure near the stations around Tainan. Thus, we conclude that the very large ground motions observed near Tainan were a result of unfortunate combination of these factors. Although this may not occur frequently, it is important to realize that even a moderate earthquake can produce unexpectedly damaging ground motions if such a circumstance occurs. Lee et al. (2016) arrived at a similar conclusion on the basis of detailed inversion of seismic and geodetic data. Our conclusion is based on direct comparisons of the observed records.

\section{COMPARISON OF THE OBSERVED AND SYNTHETIC GROUND MOTIONS OBSERVED AT SOME STATIONS}

As mentioned earlier, the station W21B is a Palert network station and the accelerograph is placed in a building, i.e., the record is not a standard free-field record. To investigate how representative the $\mathrm{W} 21 \mathrm{~B}$ ground motion is in the Tainan area, we compare in Fig. 12 the W21B records with those at nearby CWB stations TAI1 and CHN3 (Fig. 1). Although the amplitude at the station TAI1 is considerably smaller than that at $\mathrm{W} 21 \mathrm{~B}$, the amplitude at $\mathrm{CHN} 3$ is comparable to that at $\mathrm{W} 21 \mathrm{~B}$. The ground motion amplitude is strongly affected by the shallow structure with a very low 


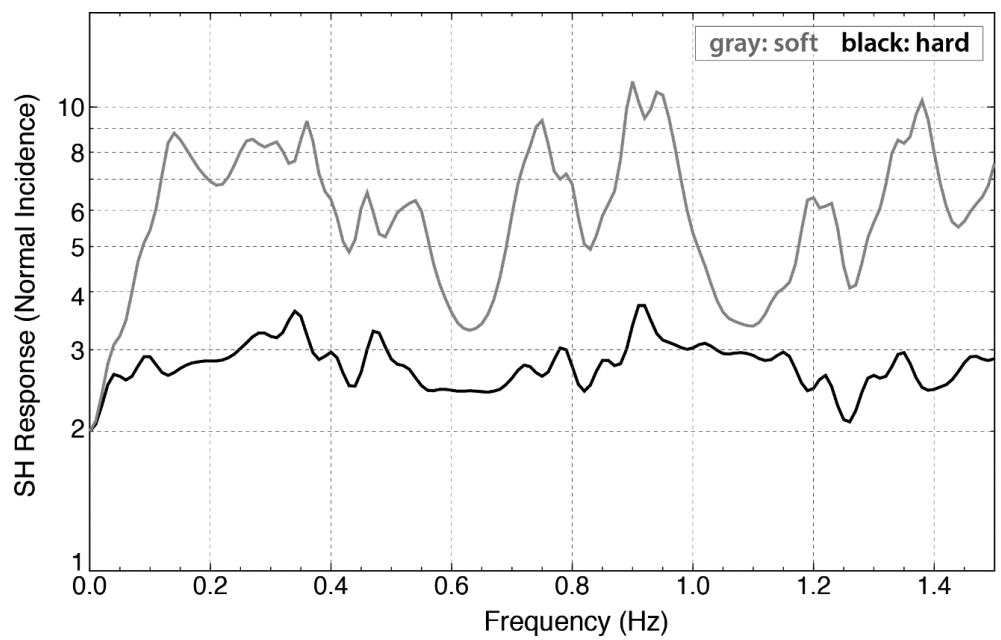

Fig. 10. Crustal response functions for a vertically incident SH waves for the "soft" (gray curve) and "hard" (black curve) crustal structure models.
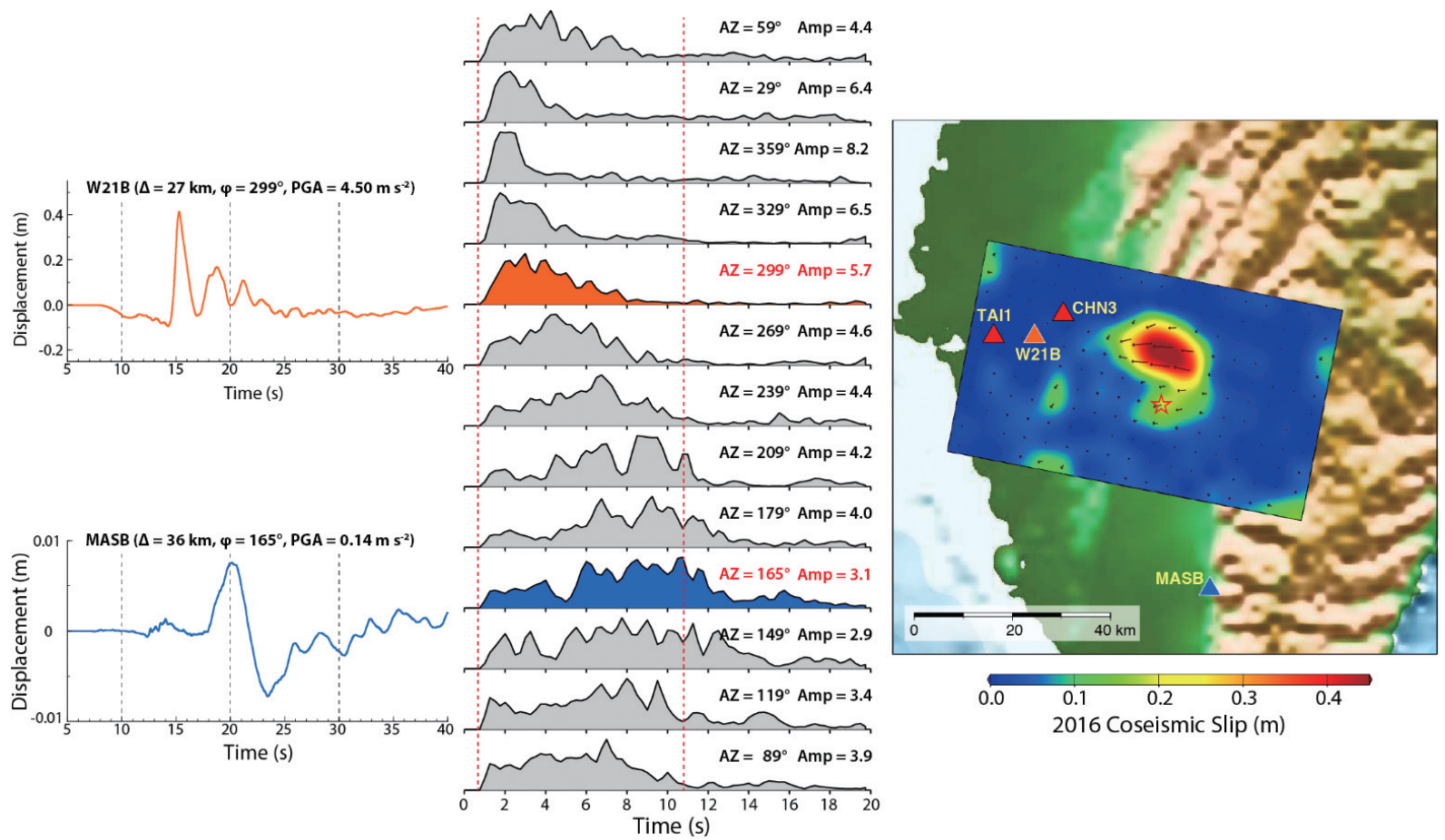

Time (s)

Fig. 11. The moment-rate functions (shaded pattern) viewed from various azimuths. The slip distribution is shown on the right. The stations W21B and MASB are located in the azimuth of $299^{\circ}$ and $165^{\circ}$. The moment-rate functions viewed from the azimuth of W21B and MASB are shown in red and blue, respectively. The displacement record at the respective station is shown for comparison. 

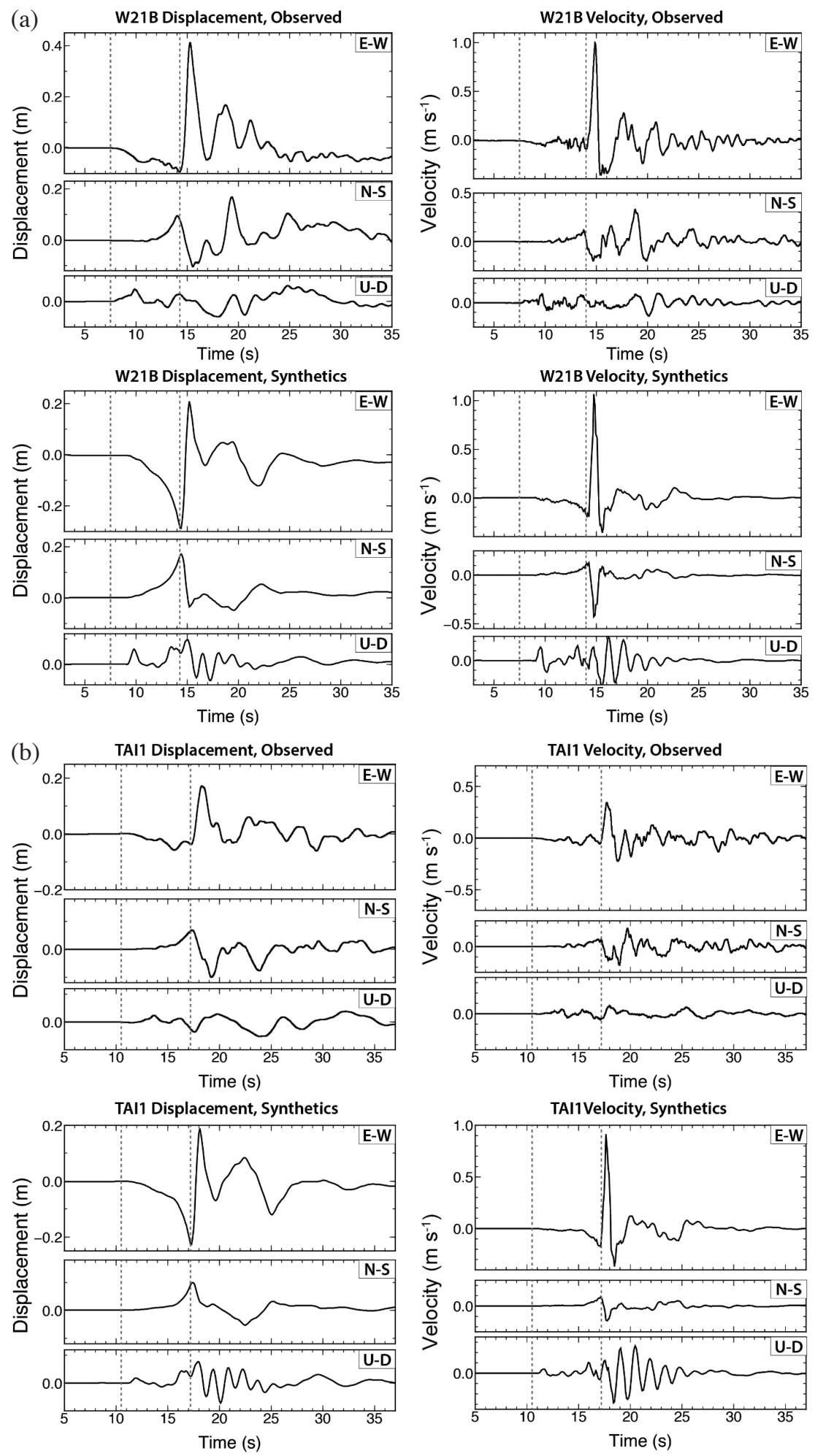

Fig. 12. Comparison of the observed (top) and synthetic (bottom) waveforms for the station (a) W21B, (b) TAI1, and (c) CHN3. Three-component displacement and velocity waveforms are shown. The "soft" crustal structure model is used. 

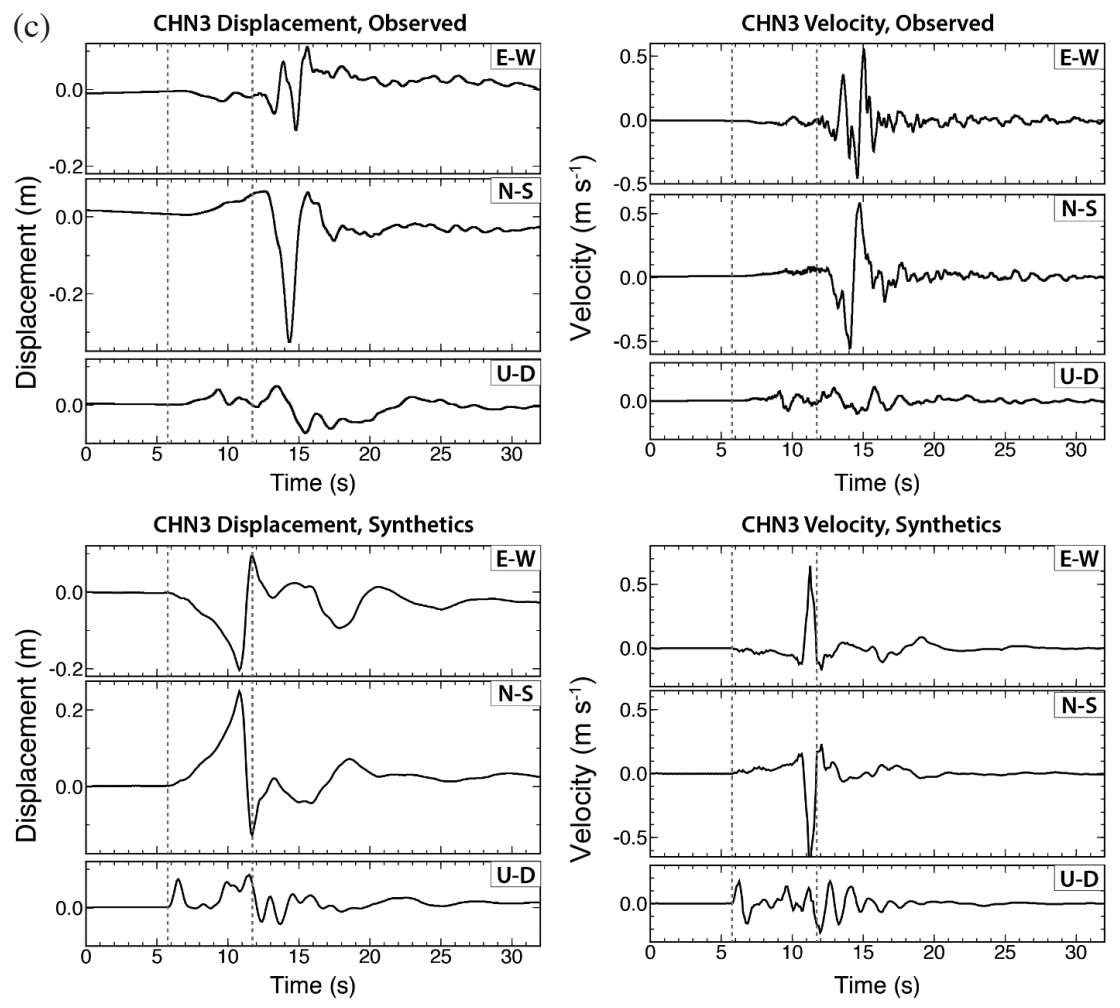

Fig. 12. (Continued)

$\mathrm{S}$-wave speed, less than $0.6 \mathrm{~km} \mathrm{~s}^{-1}$, and considerable spatial variations in amplitudes and waveforms are expected. Nevertheless, the comparable amplitudes at the stations W21B and CHN3 indicate that the large displacement and velocity amplitudes at W21B are not particularly anomalous, and can be regarded as approximate free-field values.

We compute seismograms for these stations and compare them with the observed waveforms. For this computation we use a frequency-wavenumber integration code developed by Herrmann (2013). The three-component displacement and velocity waveforms thus computed are shown in Fig. 12 for comparison with the observed. For the stations W21B, TAI1, and CHN3, we used the "soft" structure shown in Fig. 8. First, we compute an impulse response using a $0.3 \mathrm{~s}$ wide trapezoidal ( $0.1 \mathrm{~s}$ rise and fall-off times) source function using the mechanism s/d/r $=288^{\circ} / 17^{\circ} / 26^{\circ}\left(\mathrm{M}_{0}=5 \times 10^{18} \mathrm{Nm}\right)$, and convolve it with a triangular function (unit area) with a total width of $1.0 \mathrm{~s}$ to match the approximate width of the observed displacement and velocity pulses.

Given our insufficient knowledge of the 3-D structures in the area, we do not attempt to explain the every detail of the ground motion. However, the observed ground motions are approximately what are expected for those produced by the combination of the effects of radiation pattern, site effects, and directivity which all contribute toward amplifying the ground motion to the level unexpected of a moderate earthquake.
At the station MASB, the EW component displays a clear displacement and velocity pulse. The peak-to-peak displacement amplitude is only $1.4 \mathrm{~cm}$, and the pulse width is about $5.5 \mathrm{~s}$ (Fig. 13d) in contrast to the $2.7 \mathrm{~s}$ wide pulse observed at W21B (EW component). This broad pulse can be explained well with the directivity as shown in Fig. 13 . Figure 13a is the computed displacement for MASB using the "hard" crust and an impulse source. Figure 13b is an assumed source function. Figure $13 \mathrm{c}$ is the convolution of Figs. 13a and $b$ which compares well with the observed record shown in Fig. 13d. The source function shown in Fig. $13 \mathrm{~b}$ is constructed such that the initial small and the later large motions correspond, respectively, to the small slip near the hypocenter and the large slip at the patch about $10 \mathrm{~km}$ to the north shown in Figs. 4 and 11. The details are adjusted to match the observed waveform. Considering the expected moment-rate function viewed from the azimuth of MASB shown in Fig. 11, the shape of the assumed source function (Fig. 13b) is reasonable.

\section{CONCLUSION}

Although the short (1 - $1.5 \mathrm{~s}$ ) impulsive S-wave velocity pulse observed near Tainan is surprising, we conclude that the radiation pattern, path-site effects, and directivity all worked together to produce the strong S pulse. Energy focusing and trapping due to a 3-D structure most likely 

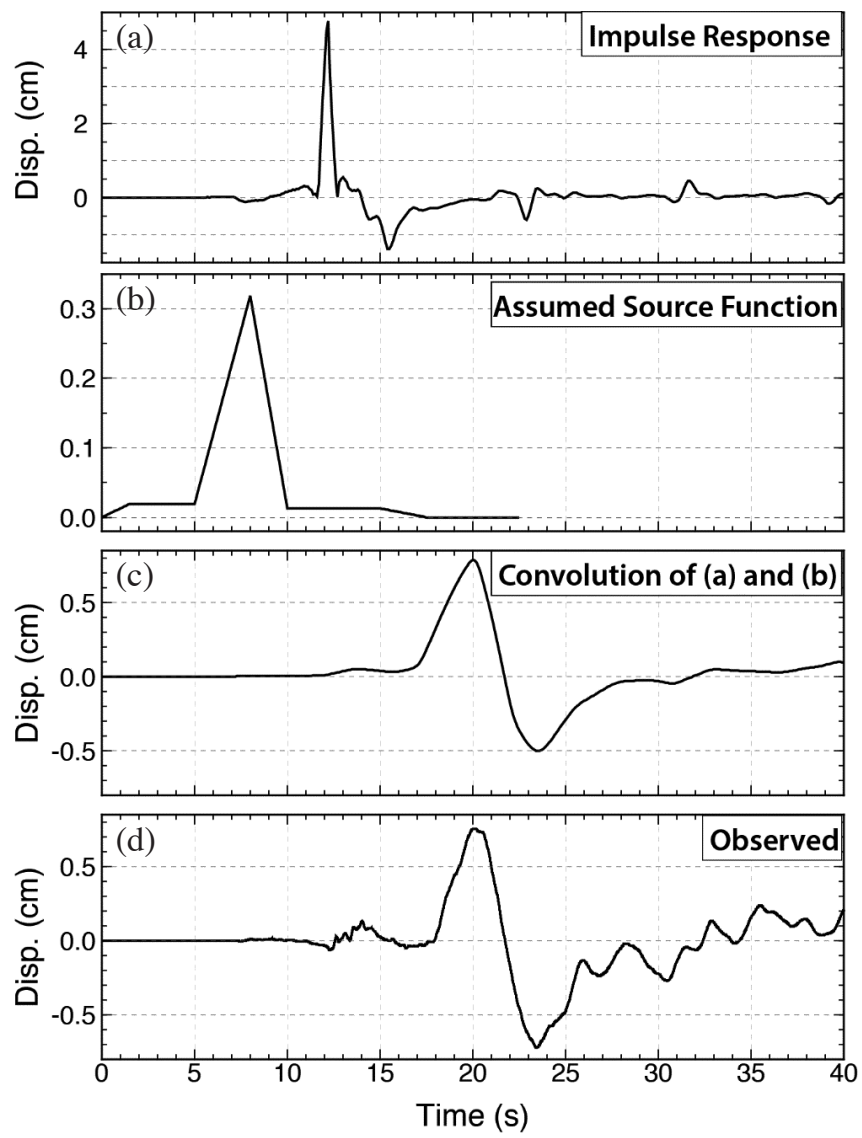

Fig. 13. Comparison of the observed and synthetic E-W component waveforms for the station MASB. The "hard" crustal structure model is used. (a) Synthetic displacement waveform computed for a trapezoidal source function with a total duration of $0.3 \mathrm{~s}$. (b) The assumed moment-rate function. (c) Convolution of (a) and (b). (d) The observed displacement waveform.

have contributed to further enhancing the effects at high frequency. More definitive confirmation would require detailed waveform studies using detailed 3-D structures. Lee et al. (2016) represents an important step toward this goal.

The result indicates that if these effects simultaneously work together toward amplifying ground motions, the extremely large ground motions as observed in Tainan can occur even for a moderate event. Such occurrences should be taken into consideration in hazard mitigation measures in the place with frequent moderate earthquakes like Taiwan.

Acknowledgements The Data Management System of the Incorporated Research Institutions for Seismology (http:// www.iris.edu/hq/) was used to access the seismic data from the Global Seismic Network and Federation of Digital Seismic Network stations. We thank Thorne Lay for providing us with useful suggestions on inversion of teleseismic data and Luis Rivera for helping us to use the Hermann's frequency-wavenumber integration code. We benefited from the discussion with The-Ru Alex Song in the early stage of this work. Part of this research was conducted while Hiroo Kanamori was visiting the Institute of Earth Sciences, Academia Sinica under the Distinguished Visiting Fellow program of Academia Sinica. We thank two anonymous reviewers for helpful comments.

\section{REFERENCES}

Hall, J. F., T. H. Heaton, M. W. Halling, and D. J. Wald, 1995: Near-source ground motion and its effects on flexible buildings. Earthq. Spectra, 11, 569-605, doi: 10.1193/1.1585828. [Link]

Hartzell, S. H. and T. H. Heaton, 1983: Inversion of strong ground motion and teleseismic waveform data for the fault rupture history of the 1979 Imperial Valley, California, earthquake. Bull. Seismol. Soc. Am., 73, 15531583.

Haskell, N. A., 1962: Crustal reflection of plane $P$ and $S V$ waves. J. Geophys. Res., 67, 4751-4768, doi: 10.1029/ JZ067i012p04751. [Link]

Heaton, T.H., J.F.Hall, D. J. Wald, and M. W.Halling, 1995: Response of high-rise and base-isolated buildings to a hypothetical $M_{\mathrm{w}} 7.0$ blind thrust earthquake. Science, 267, 206-211, doi: 10.1126/science.267.5195.206. [Link]

Herrmann, R. B., 2013: Computer programs in seismology: 
An evolving tool for instruction and research. Seismol. Res. Lett., 84, 1081-1088, doi: 10.1785/0220110096. [Link]

Huang, B. S., C. Y. Wang, D. Okaya, S. J. Lee, Y. C. Lai, F. T. Wu, W. T. Liang, and W. G. Huang, 2013: Multiple diving waves and steep velocity gradients in the western Taiwan coastal plain: An investigation based on the TAIGER experiment. Bull. Seismol. Soc. Am., 103, 925-935, doi: 10.1785/0120110047. [Link]

Huang, H. H., Y. M. Wu, X. Song, C. H. Chang, S. J. Lee, T. M. Chang, and H. H. Hsieh, 2014: Joint Vp and Vs tomography of Taiwan: Implications for subductioncollision orogeny. Earth Planet. Sci. Lett., 392, 177191, doi: 10.1016/j.eps1.2014.02.026. [Link]

Huang, M. H., H. Tung, E. J. Fielding, H. H. Huang, C. Liang, C. Huang, and J. C. Hu, 2016: Multiple fault slip triggered above the $2016 M_{w} 6.4$ MeiNong earthquake in Taiwan. Geophys. Res. Lett., 43, 7459-7467, doi: 10.1002/2016GL069351. [Link]

Hwang, R. D., G. K. Yu, W. Y. Chang, and J. P. Chang, 2003: Lateral variations of shallow shear-velocity structure in southwestern Taiwan inferred from shortperiod Rayleigh waves. Earth Planets Space, 55, 349354, doi: 10.1186/bf03351768. [Link]

IESAS (Institute of Earth Sciences, Academia Sinica, Taiwan), 1996: Broadband Array in Taiwan for Seismology, Institute of Earth Sciences, Academia Sinica, Taiwan, doi: 10.7914/SN/TW. [Link]

Kanamori, H. and L. Rivera, 2008: Source inversion of W phase: Speeding up seismic tsunami warning. Geophys. J. Int., 175, 222-238, doi: 10.1111/j.1365246X.2008.03887.x. [Link]

Kuo, C. H., K. L. Wen, C. M. Lin, S. Wen, and J. Y. Huang, 2015: Investigating near surface $S$-wave velocity properties using ambient noise in southwestern Taiwan. Terr. Atmos. Ocean. Sci., 26, 205-211, doi: 10.3319/
TAO.2014.12.02.05(EOSI). [Link $]$

Lee, S. J., T. Y. Yeh, and Y. Y. Lin, 2016: Anomalously large ground motion in the $2016 M_{\mathrm{L}} 6.6$ Meinong, Taiwan, earthquake: A synergy effect of source rupture and site amplification. Seismol. Res. Lett., 87, 13191326, doi: 10.1785/0220160082. [Link]

Lin, C. M., T. M. Chang, Y. C. Huang, H. J. Chiang, C. H. Kuo, and K. L. Wen, 2009: Shallow S-wave velocity structures in the western coastal plain of Taiwan. Terr. Atmos. Ocean. Sci., 20, 299-308, doi: 10.3319/ TAO.2007.12.10.01(T). [Link]

Liu, K. S. and Y. B. Tsai, 2005: Attenuation relationships of peak ground acceleration and velocity for crustal earthquakes in Taiwan. Bull. Seismol. Soc. Am., 95, 10451058, doi: 10.1785/0120040162. [Link]

Wu, C. F. and H. C. Huang, 2013: Near-surface shearwave velocity structure of the Chiayi area, Taiwan. Bull. Seismol. Soc. Am., 103, 1154-1164, doi: 10.1785/0120110245. [Link]

Wu, Y. M., D. Y. Chen, T. L. Lin, C. Y. Hsieh, T. L. Chin, W. Y. Chang, W. S. Li, and S. H. Ker, 2013: A highdensity seismic network for earthquake early warning in Taiwan based on low cost sensors. Seismol. Res. Lett., 84, 1048-1054, doi: 10.1785/0220130085. [Link]

Wu, Y. M., W. T. Liang, H. Mittal, W. A. Chao, C. H. Lin, B. S. Huang, and C. M. Lin, 2016: Performance of a low-cost earthquake early warning system $(P$ alert) during the $2016 M_{\mathrm{L}} 6.4$ Meinong (Taiwan) earthquake. Seismol. Res. Lett., 87, 1050-1059, doi: 10.1785/0220160058. [Link]

Ye, L., T. Lay, H. Kanamori, and L. Rivera, 2016: Rupture characteristics of major and great $\left(M_{w} \geq 7.0\right)$ megathrust earthquakes from 1990 to 2015: 1. Source parameter scaling relationships. J. Geophys. Res., 121, 826-844, doi: 10.1002/2015JB012426. [Link] 